\title{
ESTUDO SOBRE AS INTERVENÇÕES DE ENFERMAGEM FRENTE AO PACIENTE EM MORTE IMINENTE
}

\author{
Maria de Fátima Prado Fernandes ${ }^{1}$, Miriam Fujimori ${ }^{1}$, \\ Maria Sumie Koizumi2
}
FERNANDES, M. de F. P. et alii. Estudo sobre as intervençōes de enfermagem frente ao paciente em morte iminente. Rev. Bras. Enf., Brasilia, 37(2): 102-108, 1984.

\begin{abstract}
RESUMO. Trata-se de um estudo onde se procurou identificar as intervenções de enfermagem frente ao paciente em morte iminente e verificar se elas guardam relação com os valores pessoais e profissionais do enfermeiro, no que se refere à morte. As formas de intervenção de enfermagem mais freqüentemente mencionadas foram: esclarecer sobre a doença e a morte como sua conseqüência $(43,8 \%)$ para os pacientes que desejam saber porque estão morrendo e, "apoio psicológico" (36,8\%) para aqueles que recusam a morte. Os resultados obtidos demonstram ainda que, embora o enfermeiro atribua a si próprio a responsabilidade em preparar o paciente psicossócio-espiritualmente para a morte, há evidências de conflitos entre seus valores pessoais e profissionais, no que se refere à morte $e$, conseqüentemente, nas suas formas de intervenção de enfermagem.
\end{abstract}

\begin{abstract}
This is a study about nursing intervention with the patient in iminent death. This is to verify what is tre relation between nurses' personal and professional values and death. The nursing intervention often mentionated were: clear up about illness and death and theis consequence $(43.8 \%)$ to the patients who wanted to know why they were dying; and psychologic support $(36.8 \%)$ to patients who refused to die. The results demonstrated that the nurse has the responsability to prepare the patient in psychologic, social and spiritual aspects to die, but there are personal and professional conflicts about death and nursing intervention.
\end{abstract}

\section{INTRODUÇÃO}

O enfermeiro que trabalha em Unidades de Terapia Intensiva (UTIs) freqüentemente presta assistência de enfermagem a pacientes em morte iminente. Acredita-se que nessa situação crítica seus valores pessoais e profissionais poderão interferir na qualidade de sua assistência de enfermagem.

A assistência de enfermagem tem por finalidade atender as necessidades básicas do ser humano nos seus aspectos biopsicossócio-espirituais. E oportuno lembrar que essa assistência engloba proporcionar ao indivíduo uma morte tranqüila, caso este evento se apresente.

$\mathrm{O}$ atendimento das necessidades biológicas do paciente assistido em UTI é um fato evidente. Nesse particular pode-se observar a luta que o enfermeiro, assim como os demais profissionais da equipe multiprofissional, travam frente a morte.

O homem como um ser em constante evo-

- Trabalho realizado durante o Curso de Especialização em Enfermagem de Cuidados Intensivos da Escola de Enfermagem da Universidade de São Paulo.

1. Alunas do Curso de Especialização em Enfermagem de Cuidados Intensivos da Escola de Enfermagem da Universidade de São Paulo, no ano de 1982. Enfermeiras do Hospital das Clínicas da Faculdade de Medicina da Universidade de São Paulo.

2. Professor Assistente do Departamento de Enfermagem Médico-Cirúrgica da Escola de Enfermagem da Universidade de São Paulo. Orientadora do trabalho. 
lução, procura se adaptar às alterações consequientes à mutação temporal. Entretanto, independente da época, ao deparar com a morte, ele sente medo e isto é reconhecido universalmente ${ }^{13}$.

O medo da morte é inevitável e o ser humano ao enfrentá-la apresenta reações inesperadas $2,3,15,17$. Tais reações poderiam estar relacionadas com os cinco estágios vividos ao perceber a proximidade da morte. São eles: negação e isolamento, raiva, barganha, depressão el aceitação ${ }^{17}$.

Como o enfermeiro poderia intervir em cada um destes estágios que seriam enfrentados pelo paciente?

Santos ${ }^{19}$ relata que os enfermeiros declaram não ter formação suficiente para intervir em situação que envolve emoções mais profundas, como as relacionadas com a morte.

Gil ${ }^{9}$ afirma que o enfermeiro que trabalha em UTI, sabe que a morte é uma situação prevista, porém não se acha preparado para enfrentá-la.

Há concordância em que é precisu que o paciente em morte iminente seja ouvido, entendido e interpretado corretamente. $\mathrm{O}$ paciente pode, eventualmente, desejar exprimir suas necessidades, verbal ou não verbalmente, e para isto necessita de uma presença amiga, fraterna e compreensível $3,6,12,14,15,18,20$.

Como é importante a presença humana ao lado do paciente e quão significativo pode ser o simples gesto de segurar a mão do paciente, no momento de sua morte iminente.

A participação do enfermeiro junto ao paciente nesse momento parece ser de suma importância para que a assistência de enfermagem seja integral.

Ao enfermeiro compete atender o paciente como ser integral, não esquecendo de sua individualidade e, consequientemente, aceitando-o como tendo uma filosofia que lhe é peculiar ${ }^{13}$. Ao assistir o indivíduo integralmente, é preciso lembrar que a sua necessidade espiritual está também inserida nesse contexto $1,8,9,13,16$.

Para respeitar a liberdade de ser do indivíduo, o enfermeiro deveria primeiro refletir sobre seus próprios valores pessoais e profissionais.

Há, portanto, a necessidade de uma avaliação interior, onde o enfermeiro irá refletir sobre seu conhecimento como ser humano e assim assumir a responsabilidade de sua atitude profissional. Ele deve se preparar para detectar as necessidades reais do paciente como pessoa. Precisa ainda estar voltado para um compro- misso de ajuda, o qual está vinculado aos seus próprios valores $5,9,10,11,13,21$.

A reflexão sobre os nossos valores pessoais e profissionais no que diz respeito à morte, parece ser pouco questionada ou talvez nula. Acredita-se que a dificuldade, mesmo na abordagem integral ao paciente em morte iminente, está centrada nesse fato. De uma certa forma, nossas intervenções se dirigem para a manutenção da vida, já que esta parece ser percebida como um valor muito importante e a morte é vista com medo e rejeição.

Assim sendo, julga-se que a falta de uma assistência de enfermagem integral ao paciente em morte iminente, atingindo as áreas biopsicossocial-espiritual, guarda relação com os valores conflitantes do enfermeiro como pessoa e como profissional, no que diz respeito à morte.

São portanto objetivos deste trabalho:

- Identificar as necessidades de enfermagem do paciente em morte iminente, percebidas pelo enfermeiro;

- Verificar as formas de intervenção de enfermagem em relação ao paciente em morte iminente, que ele acredita serem necessárias e se ele se sente responsável por esta intervenção; e,

- Verificar se há compatibilidade entre os valores pessoais e profissionais do enfermeiro, no que se refere à morte.

\section{METODOLOGIA}

O estudo foi realizado nas .Unidades de Terapia Intensiva (UTIs) do Instituto Central do Hospital das Clínicas da Faculdade de Medicina da Universidade de São Paulo, durante o segundo semestre de 1982.

\section{População}

Foi constituída de trinta enfermeiros, que na ocasião do estudo trabalhavam em UTIs e já haviam prestado assistência de enfermagem a pacientes em estado de morte iminente. Devido à dificuldade para efetuar a entrevista, determinada para se realizar no próprio local de trabalho, a população se restringiu aos enfermeiros que se mostraram disponíveis para responder ao formulário. Foram entrevistados $52,6 \%$ dos enfermeiros que atuam nas UTIs desse hospital.

\section{Método}

A coleta de dados foi feita por meio de um formulário (Anexo), o qual foi elaborado especificamente para esta finalidade. 
Do formulário constam, além de dados de identificação do enfermeiro, nove questões em que se fundamentou o estudo efetuado. $\mathrm{Na}$ formulação das questões, se observou a necessidade de fazer um inter-relacionamento entre os valores e a atuação do enfermeiro frente ao paciente em morte iminente, pois a sua atuação parece estar diretamente relacionada aos seus valores individuais e profissionais.

Desta forma, na primeira e segunda questão foram levantados dados referentes à experiência e conhecimentos do enfermeiro no que diz respeito à morte. No caso da resposta à primeira questão ser negativa, encerrava-se a entrevista, pois, ter cuidado de pacientes em morte iminente se constituiu num dos critérios de inclusão na população de estudo.

A atuação do enfermeiro frente ao paciente que está morrendo foi abordada nas questões 3. a 7 e, uma sondagem dos valores e posicio- namento do enfermeiro frente à morte, nas questões 8 e 9 .

A entrevista foi realizada pelas próprias autoras do trabalho, alunas do Curso de Especialização em Enfermagem de Cuidados Intensivos da Escola de Enfermagem da Universidade de São Paulo.

\section{Tratamento estatistico}

Os resultados obtidos estão apresentados sob forma de tabelas em freqüência absoluta e relativa.

\section{RESULTADOS E COMENTARIOS}

A população de estudo foi constituída exclusivamente de enfermeiras que atuam no cuidado do paciente internado em UTI e que informaram ter prestado assistência de enfermagem a pacientes em morte iminente.

TABELA 1 - Número e percentual de enfermeiras segundo idade e tempo de formadas. São Paulo 1982.

\begin{tabular}{l|rrrrrrrr}
\hline & 1 & 5 & 6 & ou & & \multicolumn{2}{c}{ Total } \\
Idade & $\mathrm{N}$ & $\%$ & $\mathrm{~N}$ & $\%$ & $\mathrm{~N}$ & $\%$ \\
\hline $22-29$ & 19 & $(63,3)$ & - & $(0,0)$ & 19 & $(63,3)$ \\
$30 \quad$ ou & 4 & $(13,4)$ & 7 & $(23,3)$ & 11 & $(36,7)$ \\
\hline Total & 23 & $(76,7)$ & 7 & $(23,3)$ & 30 & $(100,0)$ \\
\hline
\end{tabular}

$\mathrm{N}=$ freqüência absoluta; $\%=$ freqüência relativa.

TABELA 2 - Número e percentual de enfermeiras segundo tempo de formadas e experiência em UTI. São Paulo, 1982.

\begin{tabular}{|c|c|c|c|c|c|}
\hline \multirow{2}{*}{$\begin{array}{l}\text { Tempo de } \\
\text { experiência }\end{array}$} & \multirow{2}{*}{$\begin{array}{r}1 \\
N\end{array}$} & \multirow{2}{*}{$\begin{array}{r}5 \\
\%\end{array}$} & \multirow{2}{*}{$\begin{array}{l}6 \text { ou }+ \\
N \quad \%\end{array}$} & \multicolumn{2}{|c|}{ Total } \\
\hline & & & & $\mathbf{N}$ & $\%$ \\
\hline $\begin{array}{l}1-5 \\
6 \text { ou }+\end{array}$ & 23 & $\begin{array}{l}(76,7) \\
(0,0)\end{array}$ & $\begin{array}{lr}5 & (16,6) \\
2 & (6,7)\end{array}$ & $\begin{array}{r}28 \\
2\end{array}$ & $\begin{array}{r}(93,3) \\
(6,7)\end{array}$ \\
\hline Total & 23 & $(76,7)$ & $(23,3)$ & 30 & $(100,0)$ \\
\hline
\end{tabular}

Em relação à idade, observa-se uma predominância daquelas da faixa etária de 22 à 29 anos $(63,3 \%)$. A maioria $(76,7 \%)$ tem de um a cinco anos, entre tempo de formada e de experiência em UTI, sendo que $93,3 \%$ têm entre um a cinco anos de experiência em UTI.

Quanto à religião, $26(86,7 \%)$ informaram ser católicas e destas, cinco $(19,2 \%)$ são praticantes. As não católicas eram em número de quatro $(13,3 \%)$ e destas, três $(75 \%)$ declararam ser praticantes.

Todas as enfermeiras responderam a cada uma das questões formuladas, sendo que algumas enunciaram: mais de uma resposta para cada questão.
A média de tempo de entrevista foi de aproximadamente 16 minutos por enfermeira.

A média de fonte de informação por enfermeira foi de 2,8. As fontes mais mencionadas foram o curso de graduação, a troca de idéias entre colegas e os livros e apostilas.

Este fato é até certo ponto surpreendente, já que, se as fontes de informação existem e se elas estão atingindo os seus usuários, as intervenções de enfermagem em relação ao paciente em morte iminente deveriam ser explícitas e inequívocas. Por outro lado, é possível que o tema morte, permaneça ao nível de conhecimento e mesmo na troca de idéias entre colegas, a segunda fonte mais mencionada, ela 
não consiga ultrapassar esse nível. Além disso, é importante lembrar que estudos sobre a morte, relacionados diretamente com a enfermagem, são escassos.

TABELA 3 - Distribuição das fontes de informações das enfermeiras em relação ao tema morte. São Paulo, 1982.

\begin{tabular}{l|ccc}
\hline & & & \\
Fonte & Sim & Não & Total \\
\hline Curso de graduação & 24 & 6 & 30 \\
Troca de idéias entre & & & \\
colegas & 18 & 12 & 30 \\
Livros e apostilas & 16 & 14 & 30 \\
Religião & 15 & 15 & 30 \\
Filmes & 5 & 25 & 30 \\
Cursos e eventos & 4 & 16 & 30 \\
de atualização & 2 & 28 & 30 \\
Outras" & & & \\
\hline
\end{tabular}

- Vivência na prática (1) e jornais (1).

Assim, embora todas as enfermeiras deste estudo já tivessem prestado assistência de enfermagem a pacientes em morte iminente, somente duas $(6,7 \%)$ informaram ter falado sobre a morte a pacientes nesta condição. Um destes pacienttes, já sabia que ia morrer, a enfermeira confirmou e chamou o capelão a pedido do próprio paciente. Para o outro paciente, a enfermeira declarou ter explicado o que é a morte.

Outro aspecto que chamou a atenção foi que as enfermeiras negaram ter falado sobre a morte com o paciente que está morrendo $(93,3 \%)$. No entanto, ao serem questionadas sobre o que achariam necessário ou o que fariam com $o$ paciente em morte iminente, a maioria enunciou formas de atuação, como se pode verificar nas Tabelas 4 e 5 .

TABELA 4 - Distribuição das necessidades de enfermagem do paciente em morte iminente, percebidas pela enfermeira. São Paulo, 1982.

\begin{tabular}{l|rc}
\hline \multicolumn{1}{c|}{ Necessidade } & $\mathrm{N}$ & $\%$ \\
\hline Apoio psicológico & 22 & 53,7 \\
Cuidado físico + tratamento & 8 & 19,5 \\
Assistência espiritual & 6 & 14,6 \\
Outras $^{*}$ & 5 & 12,2 \\
\hline Total & 41 & 100,0 \\
\hline
\end{tabular}

- Atender solicitação do paciente (2), informar o paciente sobre sua condição (1), não prolongar a vida do paciente (1) e não sabe (1).
TABELA 5 - Formas de intervenção de enfermagem segundo manifestação do paciente em relação à sua morte. São Paulo, 1982.

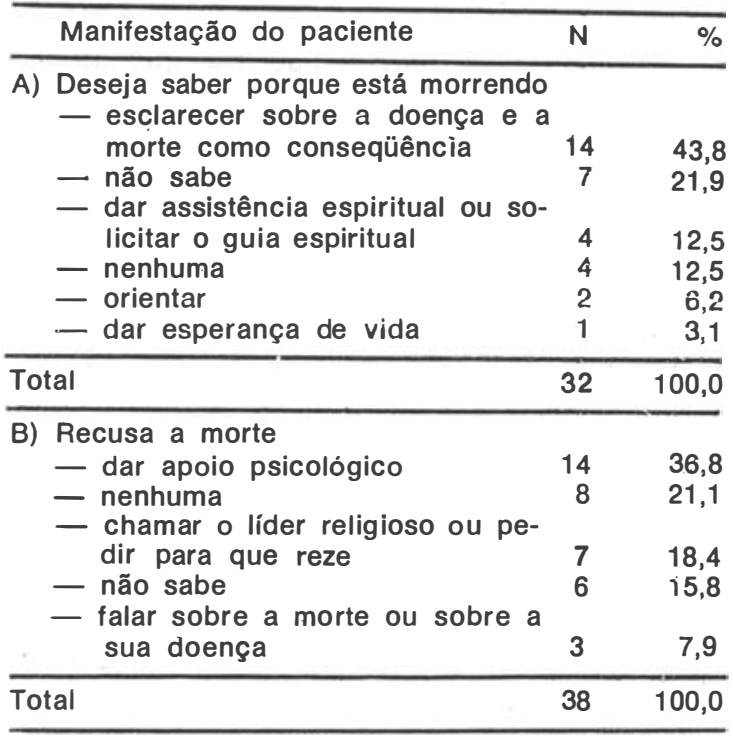

Verifica-se pela Tabela 4, que 22 respostas $(53,7 \%)$ foram mencionadas como "apoio psicológico", sendo que algumas o especificaram como uma presença humana, tranqüilizar c paciente e manter contato ou carinho.

$\mathrm{Na}$ Tabela 5, verifica-se que para o paciente que deseja saber porque está morrendo, a resposta mais frequiente foi esclarecer sobre a doença e a morte como sua conseqüência $(43,8 \%)$; e, para o paciente que está recusando a morte, dar "apoio psicológico" (36,8\%).

Considerando-se que o "apoio psicológico" foi o mais freqüentemente citado, como necessidade de enfermagem do paciente em morte iminente, percebida pela enfermeira (Tabela 4), parece estranho que a forma de atuação mais enunciada para pacientes que desejam saber porque estão morrendo, se resuma pragmaticamente em esclarecer sobre a doença e a morte como sua conseqüência (Tabela 5). Com isto, poder-se-ia pensar que a necessidade de enfermagem se baseia em concepções humanísticas e que a intervenção, por sua vez, está centrada no pragmatismo de uma realidade fisiopatológica inexorável. Será que o indivíduo que deseja saber porque está morrendo tem esta visão sobre o que lhe está ocorrendo?

Já, em relação ao paciente que está recusando sua morte, a resposta mais freqüente foi o "apoio psicológico" (36,8\%). O "apoio psicológico", praticamente, faz parte do vocabulário de enfermagem. No entanto, sua operacionalização é pouco esclarecida se considerada como um comportamento profissional. 
Sugere-se que estudos que dimensionem o que é dar "apoio psicológico"' sejam realizados.

Por outro lado, sete $(21,9 \%)$ e quatro $(12,5 \%)$ não sabem ou não têm nenhuma forma de intervenção para o paciente que deseja saber porque está morrendo. Paralelamente, oito $(21,1 \%)$ e seis $(15,8 \%)$ não têm ou não sabem como intervir junto ao paciente que está recusando a moite.

O cuidado físico, mais o tratamento, foram enunciados oito vezes $(19,5 \%)$ como uma necessidade de enfermagem do paciente em morte iminente, percebida pela enfermeira (Tabela 4). Era de se esperar que, de alguma forma, tais cuidados fossem mencionados, seja nos pacientes que desejam saber porque estão morrendo, seja para os que recusam a morte.

A maior coerência entre a necessidade de enfermagem percebida pela enfermeira e sua forma de atuação esteve centrada na assistência espiritual, porém com menor freqüência. Esta foi mencionada seis vezes $(14,6 \%)$ como necessidade de enfermagem; quatro $(12,5 \%)$ como forma de atuação para com o paciente que deseja saber porque está morrendo e sete $(18,4 \%)$ para aquele que recusa a morte.

Pela Tabela 6, observa-se que $26(86,7 \%)$ das enfermeiras consideram sua responsabilidade preparar o paciente psicossócio-espiritual- mente para a morte. Há, portanto, evidências de que a enfermeira está consciente do seu papel frente a esses pacientes, mas isto não a torna efetivamente atuante frente as necessidades por eles sentidas.

TABELA 6 - Número e percentual de enfermeiras segundo atribuição de responsabilidade no prepaparo psicossócio-espiritual do paciente em morte iminente. São Paulo, 1982.

\begin{tabular}{|c|c|c|}
\hline Responsabilidade & $\mathbf{N}$ & $\%$ \\
\hline $\begin{array}{l}\text { Enfermeira } \\
\text { Enfermeira }+ \text { equipe } \\
\text { multiprofissional } \\
\text { Equipe multiprofissional excluindo a } \\
\text { enfermeira }\end{array}$ & $\begin{array}{r}14 \\
12 \\
4\end{array}$ & $\begin{array}{l}46,7 \\
40,0 \\
13,3\end{array}$ \\
\hline Total & 30 & 100,0 \\
\hline
\end{tabular}

Nas respostas enunciadas pelas enfermeiras, a identificação dos valores pessoais do paciente, como um aspecto primordial a ser levantado e nos quais se norteiam a assistência de enfermagem individualizada, não foi percebida. No entanto, há concordância em que é necessário que o paciente em morte iminente seja ouvido, entendido e interpretado corretamente e, que a expressão de suas necessidades pode se efetivar verbal ou não verbalmente $3,6,12,14,15,18,20$.

TABELA 7 - Distribuição do significado da morte segundo análise pessoal, profissional e da sua própria morte. São Paulo, 1982.

\begin{tabular}{|c|c|c|c|c|c|c|}
\hline \multirow{2}{*}{$\overbrace{\text { Significado }}^{\text {Análise }}$} & \multirow{2}{*}{\multicolumn{2}{|c|}{ Pessoal }} & \multicolumn{2}{|c|}{ Profissional } & \multicolumn{2}{|c|}{$\begin{array}{l}\text { Da sua próprla } \\
\text { morte }\end{array}$} \\
\hline & & & & $\%$ & $\mathrm{~N}$ & $\%$ \\
\hline $\begin{array}{l}\text { Um fato natural } \\
\text { Rejeição, temor, tristeza } \\
\text { Continuidade, viagem } \\
\text { O fim de tudo } \\
\text { Não soube responder } \\
\text { Não sente medo } \\
\text { Alegria }\end{array}$ & $\begin{array}{r}5 \\
14 \\
7 \\
4 \\
2 \\
- \\
-\end{array}$ & $\begin{array}{l}(15,6) \\
(43,9) \\
(21,8) \\
(12,5) \\
(6,2) \\
(0,0) \\
(0,0) \\
\end{array}$ & $\begin{array}{r}18 \\
4 \\
2 \\
3 \\
2 \\
- \\
-\end{array}$ & $\begin{array}{l}(62,4) \\
(13,7) \\
(6,8) \\
(10,3) \\
(6,8) \\
(0,0) \\
(0,0) \\
\end{array}$ & $\begin{array}{r}2 \\
16 \\
7 \\
7 \\
4 \\
2 \\
3 \\
\end{array}$ & $\begin{array}{l}(5,7) \\
(48,7) \\
(0,0) \\
(20,0) \\
(11,4) \\
(5,7) \\
(8,5) \\
\end{array}$ \\
\hline Total & 32 & $(100,0)$ & 29 & $(100,0)$ & 35 & $(100,0)$ \\
\hline
\end{tabular}

Pela Tabela 7, verifica-se que a morte adquiriu diferentes significados, se analisada sob o ponto de vista pessoal, profissional ou da sua própria morte. Do ponto de vista profissional é mais frequientemente analisada como um fato natural $(62,4 \%)$, mas como pessoa ou analisando a sua própria morte, é vista com rejeição, temor ou tristeza $(43,9 \%$ e $48,7 \%)$.

E interessante lembrar, que há um interrelacionamento entre o ser Pessoa e o ser Enfermeiro e, conseqüentemente, o ser Enfermagem ${ }^{16}$. Assim sendo, seria possível deixar o ser Pessoa e assumir somente o ser Enfurmeiro, ou há necessidade de ambos para atuar como o ser Enfermagem?

A necessidade de enfermagem do paciente em morte iminente, percebida pela enfermeira e mais frequientemente enunciada, foi o "apoio psicológico" (53,7\%). Assim, mesmo sem questionar o que seria realmente esse "apoio psicológico", a forma como ele seria manifestado parece ser controvertida, já que o ser Pessoa, vê a morte com rejeição, temor e tristeza, e o ser Enfermeiro, como um fato natural.

Outro aspecto que chamou a atenção nos resultados obtidos é que para os pacientes que desejam saber porque estão morrendo, a res- 
posta mais frequiente foi esclarecer sobre sua doença e a morte como consequiência (Tabela 5). De certa forma, pode-se pensar que nesta situação prevaleceu o ser Enfermeiro que encara a morte como um fato natural. Julga-se no entanto, que a assistência individualizada requer do enfermeiro, como passo inicial, a identificação dos problemas sentidos pelo paciente.

Foi surpreendente verificar que em momento algum se mencionou a dificuldade na comunicação verbalizada, que freqüentemente ocorre com esses pacientes em UTIs, seja porque ele pode estar intubado ou traqueostomizado, seja porque apresenta alterações no nível de consciência. Igualmente a comunicação não verbalizada também não foi mencionada.

Outrossim, considerando-se que grande parte do nosso comportamento se manifesta através da comunicação não verbalizada e, que há evidências de conflito entre os valores do ser Pessoa e do ser Enfermeiro no que se refere à morte, sugere-se que discussões e estudos sobre o conhecimento de si mesmo se tornem mais efetivos.

\section{CONCLUSOES}

Frente aos objetivos propostos neste estudo, verificou-se que:

- As necessidades de enfermagem do paciente em morte iminente, percebidas pelas enfermeiras, referem-se ao "apoio psicológico" $(53,7 \%)$ cuidados físicos e tratamento $(19,5 \%)$ e assistência espiritual $(14,6 \%)$;

- As formas de intervenções de enfermagem mais freqüentemente mencionadas foram esclarecer sobre a doença e a morte como consequiência $(43,8 \%)$, para os pacientes que desejam saber porque estão morrendo e, "apoio psicológico" $(36,8 \%)$ para aqueles que recusam a morte;

\section{REFERENCIAS}

1. ARAƯJO, C. P. Filosofia individual de enfermagem. Enf. Novas Dimens., São Paulo, 2 (4): 197-9, set./out. 1976.

2. BECKER, E. A negação da morte. Rio de Janeiro, Interamericana, 1978.

3. BIRD, B. Conversando com o paciente. 2. ed. São Paulo, Manole, 1975.

4. CASTEllanos, B. E. P. Filosofia de enfermagem baseada em valores pessoais. Enf. Novas Dimens., São Paulo, 3 (2): 93-6, mar./abr. 1977.

5. CHIDA, A. M. Como o ser enfermeiro pensa a realidade ser enfermagem. Enf. Novas Dimens., São Paulo, 5 (2): 57-60, mar./abr. 1979.
- O significado do que é "apoio psicológico" e como ele se efetiva na intervenção de enfermagem precisa ser melhor esclarccido;

- $86,7 \%$ das enfermeiras atribuem a si próprias ou a si e aos demais profissionais da equipe multiprofissional de saúde, a responsabilidade em preparar psicossócio-espiritualmente 0 paciente para a morte;

- Há evidências de conflito entre valores pessoais e profissionais no que se refere à morte. Sob o ponto de vista profissional, a morte foi analisada pelas enfermeiras, com maior freqüência, como um fato natural $(62,1 \%)$ e, com rejeição, temor ou tristeza, se analisado no aspecto pessoal $(43,9 \%)$ e sobre sua própria morte $(48,7 \%)$.

\section{RECOMENDAÇÓES}

Baseadas nos resultados obtidos, recomenda-se que:

- Nas escolas de enfermagem, se promovam atividades onde haja discussão sobre a tríade ser Pessoa, ser Enfermeiro e ser Enfermagem, a fim de minimizar os efeitos dos nossos conflitos interiores na assistência de enfermagem que é prestada aos pacientes em morte iminente.

- As enfermeiras, hospitalares e docentes, que atuam em UTI, junto aos pacientes em morte iminente, procurem formas de promover uma assistência de enfermagem eficaz, não somente por meio de sua atuação individual, mas desenvolvendo e divulgando estudos controlados sobre sua efetividade.

- Ao se promover atividades de reciclagem da equipe de enfermagem, sejam incluídos os aspectos de assistência psicossócio-espiritual aos pacientes em morte iminente.

FERNANDES, M. de F. $P$. et alii Study of the nursing intervention in iminent death of patient. Rev. Bras. Enf., Brasília, 37(2): 102-108, 1984.

\section{BIBLIOGRAFICAS}

6. DUGAS, B. W. Enfermagem prática. 3 ed. Rio de Janeiro, Interamericana, 1978.

7. FELIX, M. A. F. A realidade ser enfermagem vista pelo enfermeiro. Rev. Gaúcha Enf., Porto Alegre, 3 (1): 19-21, dez. 1981.

8. FELDMANN, M., irmã. Terceira dimensão em enfermagem: assistência psicossocial e espiritual. Mundo Saúde, São Paulo, 4 (15): 167$170,1980$.

9. GIL, L. Una enfermera ante la muerte. In: ALVAREZ, F. et alii. Morir con dignidad. Madrid, Marova, 1976. p. 67-71.

10. KRON. T. Manual de enfermagem. Rio de Janeiro, Interamericana, 1976. p. 105. 


\section{ANEXO}

\section{Formulárlo}

Dados de identificação

UTI

Data da entrevista

$/ 1982$.

Tempo de formada

Tempo de experiência em UTI

Função exercida na UTI

Idade

anos.

Sexo

Religião ou crença:

Praticante: Sim ( ) Não ( ) As vezes ( ).

Duração da entrevista: início: às horas. término: às horas.

\section{Perguntas:}

1. Você já teve oportunidade de prestar assistência de enfermagem a pacientes de UTI em fase de morte iminente?

$\operatorname{Sim}($ ) Não ( )

2. Quais foram suas fontes de informação a respeito do tema morte:

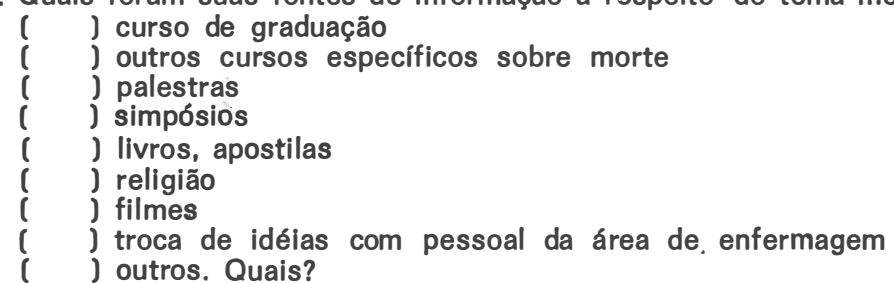

3. Você já falou sobre morte para um paciente que está morrendo? Não ( ) Caso sim: Como o fez?

4. $O$ que você acha mais necessário para o paciente que está morrendo?

5. $O$ que você faria com um paciente que deseja saber por que está morrendo?

6. $O$ que você faria com um paciente que está recus ando sua morte?

7. Você considera função do enfermejro preparar o paciente psicossócio-espiritualmente para a morte? Sim ( ) Náo ( )

Caso não: Você acredita que

( ) é responsabilidade médica

( ) é responsabilidade do fisioterapeuta

( ) é responsabilidade do psicólogo

( ) é responsabilidade do guia espiritual

( ) o enfermeiro não dispõe de tempo para mais esta função

( ) o enfermeiro não sabe o que dizer

( ) o enfermeiro não tem preparo para esta situação

( ) outras - Quais?

8. Como você analisa a morte:

- como pessoa

- como enfermeiro

9. O que significa para você a sua própria morte? 